\title{
Effect of sprouting on anthocyanin, antioxidant activity, color intensity and color attributes in purple sweet potatoes
}

\author{
*Yudiono, K. and Kurniawati, L. \\ Department of Agricultural Product Technology, Faculty of Agriculture, Widya Karya Catholic University, \\ Malang 65115, East Java, Indonesia
}

\author{
Article history: \\ Received: 13 October 2017 \\ Received in revised form: 6 \\ November 2017 \\ Accepted: 7 November 2017 \\ Available Online: 13 \\ November 2017
}

\section{Keywords:}

Anthocyanin,

Antioxidant activity,

Color intensity,

Sprouting,

Purple sweet potato

\section{DOI:}

https://doi.org/10.26656/fr.2017.2(2).252

\begin{abstract}
Sweet potatoes stored in a humid state will generally sprout, leading to them being deemed inedible by customers. During the sprouting process enzyme activities increase and as such it was assumed that there had been changes in the nutrition and secondary metabolism compounds, e.g. anthocyanins. The purpose of this research was to investigate the changes occurred in the characteristics of anthocyanins during the purple sweet potatoes' sprouting. One-factor Randomized Block Design was used in the research design, i.e. the sprouting time in 6 stages: 1, 2, 3, 4, 5, and 6 weeks. The results showed that the highest antioxidant activity is $51.61 \pm 2.11 \%$, the highest color intensity is $0.72 \pm 0.72$, and the lowest hue angle value or the lowest $h$ is $30.75 \pm 0.93^{\circ}$, occurring in the 4 th week of sprouting. While the highest total anthocyanin is $222.07 \pm 2.65 \mathrm{mg} / \mathrm{kg}$ wet weight, and the highest red color value or $\mathrm{a}^{*}$ is $12.80 \pm 0.49$, occurring in the $3 \mathrm{rd}$ week of sprouting. The major components that compose purple sweet potatoes are Cyanidin-3-0-glucoside $\left([\mathrm{M}-\mathrm{X}]^{+}=\mathrm{m} / \mathrm{z} 286.50\right.$ to 287.50 and $\left.[\mathrm{M}]^{+}=\mathrm{m} / \mathrm{z} 449\right)$ and Peonidin $-3,5-0$-diglucoside $\left([\mathrm{M}-\mathrm{X}]^{+}=\mathrm{m} / \mathrm{z} 462.50\right.$ to 463.50 and $\left.[\mathrm{M}]^{+}=\mathrm{m} / \mathrm{z} 625\right)$.
\end{abstract}

\section{Introduction}

The use of synthetic coloring in food products is unsafe since they contain heavy metals, such as lead, which are harmful to health as they could trigger lethal diseases such as tumors and cancer (Yudiono, 2011). According to WHO (2007), cancer cases were expected to experience $57 \%$ surge worldwide in the next 20 years; it is further stated that new cancer cases would rise from about 14 million to 22 million within two decades and cancer deaths were expected to increase from 8.2 million to 1 million annually. It is estimated that by 2030 there will be an increase of cancer patients in Indonesia by seven times and it is estimated that there will be 100 new cases per 100,000 people each year. This means that of 237 million people there will be approximately 237,000 new cancer patients per year (Kartika, 2013). The longterm purpose of this research is to determine bioactive compounds contained in the anthocyanin which could serve as anti-cancer.

Cyanidin is one type of anthocyanin particularly found in purple sweet potatoes and reported to have the capability as an antimutagen and anti-cancer, as well as very beneficial for the health of eyes and the retina (Yoshimoto et al., 1999). In addition, the purple pigment of purple sweet potatoes has functional properties for health, i.e. as an antioxidant, anti-cancer, capable of preventing liver damage and lowering blood sugar levels, and as antihypertensive (Suda et al., 2003). According to research conducted by Katsube et al. (2003) and Zhang et al. (2002), anthocyanins isolated from Vacciniummyrtillus plants, fruits, and vegetables were successfully proven as a bioactive compound that could inhibit the growth of cancer cells in humans. Glycosides from anthocyanins which have been successfully identified to inhibit the growth of cancer cells include Cyanidin, Delphinidin, Malvidin, Pelargonidin, and Petunidin.

When there is abundance in sweet potato production, excess products that the farmers are unable to sell or are unprocessed are usually put into storage. However, during the storage some sweet potatoes experience sprouting; and consequently, deemed to be damaged and are ultimately not used. The process of seed sprouting is a complex series of changes in morphology, physiology, and biochemistry. The factors affecting sprouting consist of internal and external factors. Internal factors include maturity and seed size, dormancy, and hormones. External factors include water, temperature, oxygen, and light. During the sprouting process enzyme activities will 
increase so there will be changes in nutrition and secondary metabolism compounds, such as anthocyanin (Umnajkitikorn et al., 2013).

The purpose of this study was to investigate the changes occur in the characteristics of anthocyanin during the sprouting of sweet potatoes.

\section{Materials and methods}

\subsection{Plant materials}

The raw material employed is sweet potato tubers of Ayamurasaki variety harvested from Research Center for Assorted Beans and Tuber Crops's (Balitkabi's) experimental field in Malang, Indonesia (during the dry season).

\subsection{Preparation of sweet potato tuber sprouting experiment}

The sweet potato tuber selected was of Ayamurasaki variety which was then carefully washed. Each tuber piece was put into a bottle or a glass filled with sterilized water, wherein the piece was placed half-submerged in the water. Toothpicks were used to hold the tubers in place for sprouting. The experiment design employed was one-factor Randomized Block Design (RBD), i.e. the length of the sprouting consists of six stages $(1,2,3$, $4,5,6$, and 7 weeks) repeated two times. Observation variables include total anthocyanin content, antioxidant activity, color intensity, color size, and the profiles of anthocyanin components. The statistical analysis employed to find out the effects of the treatment was the analysis of variance (ANOVA), using the Design Expert 7.0.0 program; treatments were differentiated when $\mathrm{p}$ value $<0.05$, but no differentiation was made when $p$ value $>0.05$.

\subsection{Extraction of anthocyanin and analysis of} anthocyanin levels using rapid quantification method

Extraction of anthocyanin and analysis of anthocyanin levels was performed using rapid quantification method (Abdel-Aal and Hucl, 1999). Three grams of Ayamurasaki purple sweet potato samples were blended and weighed, and $24 \mathrm{ml}$ ethanol $96 \%$ was added (1:8), then the whole mixture was acidified (ethanol: HCL $1.0 \mathrm{~N}=35: 15$ ), and finally stirred for 15 minutes using magnetic stirrer. Once completely blended, the mixture was centrifuged at 4000 rpm for 15 minutes until a supernatant was obtained. The supernatant was poured into a $50 \mathrm{ml}$ flask and filtered through a Whatman filter paper (number 1) to obtain the filtrate/concentrate of pulp-free anthocyanin. Next, acidified ethanol was added to the filtrate until $50 \mathrm{ml}$ volume was achieved. Nitrogen was blown over the bottled filtrate/concentrate to eliminate oxygen in the headspace, and then it was stored in the refrigerator at $4^{\circ}$
$\mathrm{C}$ temperature until further use.

\subsection{Total anthocyanin}

The measurement of anthocyanin was following the method described by Abdel-Aal and Hucl, (1999). Four $\mathrm{ml}$ of the filtrate/concentrate were taken, and its absorbance was measured at $532 \mathrm{~nm}$ wavelength using a spectrophotometer.

Total anthocyanin calculation:

$C=(A / \mathrm{e}) \times(\mathrm{Vol} / 1.000) \times \mathrm{MW} \times(1 /$ sample weight $) \times 10^{6}$

Where $\mathrm{C}=$ concentration of total anthocyanin $(\mathrm{mg} / \mathrm{kg}) ; A$ $=$ reading of absorbance; $\mathrm{e}=$ molar absorptivity (cyanidin 3-5-diglucoside $=25.965 \mathrm{~L} / \mathrm{mol}$ ); $\mathrm{Vol}=$ total volume of anthocyanin extract in $50 \mathrm{ml}$ flask and $\mathrm{MW}=$ the weight of the molecules of cyanidin 3-5-diglucoside (449)

\subsection{Change to antioxidant activity}

The antioxidant activity of samples was determined using The DPPH by Bland-Williams et al. (1995). Four $\mathrm{ml}$ of extraction filtrate was added with $1 \mathrm{ml}$ of DPPH solution at the concentration of $0.2 \mathrm{~nm}$, allowed to stand for 30 minutes, taken as much as $1 \mathrm{ml}$ and had its absorbance measured at $\lambda 517 \mathrm{~nm}$.

The effects of DPPH capture $(\%)=[(\mathrm{Ao}-\mathrm{A} 1 / \mathrm{Ao}) \times 100]$

Where Ao $=$ absorbance of the control or without the addition of the extract and $\mathrm{A} 1=$ absorbance of sample

\subsection{Color intensity}

Color intensity was determined according to FAO (1984). A buffer solution of citric acid-dibasic sodium phosphate, $\mathrm{pH} 3.0$, was prepared as much as $200 \mathrm{ml}$ in the following way: $159 \mathrm{ml}$ of $2.1 \%$ citric acid solution was mixed with $41 \mathrm{ml}$ of $0.16 \%$ dibasic sodium phosphate solution. Then, the $\mathrm{pH}$ was adjusted to $\mathrm{pH} 3$ using citric acid solution or dibasic sodium phosphate solution. The sample $(20 \mathrm{mg}$ of which was diluted in 25 $\mathrm{ml}$ flask using buffer solution of citric acid - dibasic sodium phosphate $\mathrm{pH}$ 3) had its absorbance measured (A) at the cuvette of $1 \mathrm{~cm}$ thickness, at maximum wavelength (515 $\mathrm{nm}$ for cyanidin-3-glucoside) so that the absorbance was measured at 0.2 to 0.7 . The solution of citric acid - dibasic sodium phosphate pH 3.0 was used as a control. The determination of color intensity is carried out through the following formula:

$$
\text { Colour intensity }=\frac{\mathrm{A} \times 25}{\text { sample weight }}
$$




\subsection{Color attributes}

The size of the color of samples was determined using the method by Andarwulan et al. (2011). The liquid filtrate from the extraction was prepared in a glass, the color reader (Konika Minolta CR-100) was turned on and reading target was set $L^{*}, a^{*}, b^{*}, h$ using color reader.

Description: $\mathrm{L}^{*}=$ dark-light (lightness); $\mathrm{a}^{*}=$ red value; $\mathrm{b}^{*}=$ yellow value; $\mathrm{h}=$ hue angle (color).

\subsection{Anthocyanin profile with $L C-M S / M S$}

Anthocyanin profile was determined using the LCMS/MS method (Ling et al., 2009). The optimal anthocyanin content of the extraction results during sprouting treatment (the results of $3^{\text {rd }}$ week sprouting) was measured as much as $5 \mathrm{ml}$ in a centrifuge tube and then was dissolved in $10 \mathrm{ml}$ of acetonitrile solvent, shaken for 1 minute, followed by sonification, for 30 minutes, and centrifugation at $3000 \mathrm{rpm}$ for 30 minutes. The supernatant was transferred to a centrifuge tube and dried at $90^{\circ} \mathrm{C}$. The result of centrifugation was added with $5 \mathrm{ml}$ acetonitrile, then given sonification for 15 minutes, and was centrifuged at $3000 \mathrm{rpm}$ for 30 minutes. The supernatant was filtered through a $0.2 \mu \mathrm{m}$ filter membrane and then put into a vial. The vial was inserted into the auto sample at LC-MS/MS, ready to be injected as much as $5.10 \mu \mathrm{L}$ for analysis.

\subsection{LC-MS/MS operating conditions}

The column used was Hypersil Gold specification (50 $\mathrm{mm} \times 2.1 \mathrm{~mm} \times 1.9 \mu \mathrm{m})$; UHPLC ACCELLA brand type 1250 , made by Thermo Scientific, which consists of degasser vacuum, quarter pump, thermostatic autosampler controlled by a personal computer with xCalibur 2.1 program; Mobile-phase A which consists of $0.1 \%$ formic acid in aquabidest, phase B which consists of $0.1 \%$ formic acid in Acetonitrile.; a linear gradient with the speed of $300 \mu \mathrm{l} / \mathrm{min}$ with motion phases control as follows: a) $0-0.6$ minutes $15 \% \mathrm{~B}$, b) $2-3.5$ minutes $100 \% \mathrm{~B}$, and c) 4.5 minutes $15 \% \mathrm{~B}$. Injection volume at the $\mathrm{LC}$ was $2 \mu \mathrm{L}$. The column was maintained at $30^{\circ} \mathrm{C}$ and the autosampler compartment was established at $10^{\circ}$ C.

Equipment employed was triple Q (quadruple) MS/ MS mass spectrometer TSQ QUANTUM ACCESS MAX of Thermo Finnigan with the ionization source of ESI (Electrospray Ionization) controlled by TSQ Tune software operating in Positive mode. From C3G molecule with precursor ion of $449 \mathrm{~m} / \mathrm{z}$ transition, ion $287 \mathrm{~m} / \mathrm{z}$ was obtained. Whereas from precursor ion P3, 5 -O-DG $625 \mathrm{~m} / \mathrm{z}$ transition ion 463; $301 \mathrm{~m} / \mathrm{z}$ was obtained. The conditions of ESI ionization are as follows: spray voltage $3 \mathrm{kV}$, evaporation temperature $270^{\circ} \mathrm{C}$, capillary temperature $300^{\circ} \mathrm{C}$, nitrogen as sheath gas pressure $40 \mathrm{psi}$, and Aux gas pressure 10psi with argon.

\section{Results and discussion}

\subsection{Total anthocyanin content and antioxidant activity}

Total anthocyanin content and antioxidant activity are presented in Table 1. Based on the results of measurements of total anthocyanin content and antioxidant activity, the sweet potato tubers left to sprout for 7 weeks (42 days) showed an increase in the anthocyanin content every 7 days of observation. The highest total anthocyanin content was obtained in the $3^{\text {rd }}$ week of sprouting, i.e. $222.07 \pm 2.65 \mathrm{mg} / \mathrm{kg}$ wet weight, while the highest antioxidant activity was obtained in the $3^{\text {rd }}$ and $4^{\text {th }}$ week of sprouting, i.e. $49.11 \pm 0.82$ and $51.61 \pm 2.11 \%$. The increase in the sweet potato tubers' anthocyanin content during the sprouting process is assumed to be due to the increase of enzymes' activities in the ingredients, including that of the anthocyaninforming enzymes such as PAL (phenylalanine ammonia lyase) enzyme. The results of the study of Kubasek et al. (1992) suggested that the anthocyanin pigments of the Arabidopsis seeds occurred after sprouting, was related to the increased of mRNA coded by 4 flavonoid biosyntheses such as PAL7 (encoding fenilalaninamonialiase I), CHS (encoding chalcone synthase), CHI (encoding chalconeisomerase), and DFR (encoding dihydroflavonolreductase).

Table 1 . The average values of total anthocyanin $(\mathrm{mg} / \mathrm{kg}$ of wet tubers) and antioxidant activity (\%) during sprouting process*

\begin{tabular}{ccc}
\hline $\begin{array}{c}\text { Sprouting } \\
\text { week }\end{array}$ & Total Anthocyanin & Antioxidant Activity \\
\hline 1 & $213.13 \pm 1.24^{\mathrm{c}}$ & $43.45 \pm 0.95^{\mathrm{a}}$ \\
2 & $218.89 \pm 1.10^{\mathrm{e}}$ & $46.50 \pm 0.20^{\mathrm{b}}$ \\
3 & $222.06 \pm 2.65^{\mathrm{fe}}$ & $49.11 \pm 0.82^{\mathrm{cd}}$ \\
4 & $216.35 \pm 2.02^{\mathrm{de}}$ & $51.61 \pm 2.11^{\mathrm{d}}$ \\
5 & $194.62 \pm 1.51^{\mathrm{b}}$ & $47.83 \pm 1.70^{\mathrm{c}}$ \\
6 & $153.04 \pm 0.71^{\mathrm{a}}$ & $46.28 \pm 1.02^{\mathrm{b}}$ \\
\hline
\end{tabular}

* Values are means with standard deviation from three different samples. Different alphabet superscript in one column indicate significant difference $(p<0.05)$.

Besides that, the results of the research on the antioxidant activity is in line with the research by (Begam and Sharanavan 2011; Suryanti et al., 2016; Jirapa et al., 2016; Phattayakorn et al., 2016), despite using different commodities (groundnut arachis H., Leucaena L., and Paddy rice). The results of these studies show that the commodity undergoes germination will increase its antioxidant activity. The increase of antioxidant capacity is allegedly due to the increased activity of enzymes involved in the capture of free 
radicals and peroxides. According to Parmooon et al. (2013), the enzyme playing the role in the capture of free radicals and peroxides are superoxide dismutase (SOD). This is supported by the results of the research of Vichit and Soewan, (2016) in which rice that undergoes germination its SOD is 3 times higher than those not experiencing germination.

\subsection{Color intensity and color attributes $\left(a^{*}, L^{*}, b^{*}\right.$ and} h)

The measurement results of intensity of colors and colors sizes are presented in Table 2. Color intensity shows increased sprouting which reached its highest at week 4 at $0.72 \pm 0.72$, then at week 3 it was $0.70 \pm 0.7$. Based on the averages and standard deviation, it is revealed that sprouting treatment at week 3 and 4 yielded not different values. Seen from its standard deviation, however, sprouting treatment at week 3 is the chosen treatment due to its smaller standard deviation. The high values of color intensity indicate the sharpness of the red color since the test used a wavelength $(\lambda)$ of $515 \mathrm{~nm}$ which is the maximum $\lambda$ for cyanidin. These changes in color intensity are consistent with the changes in anthocyanin content during sprouting.

The values of the color strengths of magenta to red $\left(a^{*}\right)$ at the beginning of sprouting show an increase which reached its highest at week 3 at $12.80 \pm 0.49$. This $a^{*}$ value was consistent with the results of total anthocyanin, so it may be inferred that the increase in $\mathrm{a}^{*}$ value was related to the increase in the anthocyanin content.

$\mathrm{L}^{*}$ value (dark-bright) shows a tendency to increase during sprouting and the highest value is reached during week 4 sprouting at $21.5 \pm 2.45$, but with all those sprouting treatments no differences occur. An increased $\mathrm{L}^{*}$ value shows an increase in the brightness of the color. When linked to $\mathrm{a}^{*}$ value, there seems to be a contradiction since the patterns of $a^{*}$ value should have been the opposite of $\mathrm{L}^{*}$ value, in other words, when $\mathrm{a}^{*}$ value increases $\mathrm{L}^{*}$ value should decrease. This is likely due to the increase of water content in the tubers during sprouting because during the sprouting treatment the sweet potato tubers were immersed in water so water was absorbed into the tubers. This increase in water resulted in the dilution of many compounds in the tubers, so the light in the color reader mostly just passed through.

Color attribute $b^{*}$ value represents the yellow color, meaning the higher the color yellow or green the more dominant it is. The patterns of $b^{*}$ value decreased to week 4 . That is, until week 4 the color yellow had changed to the color red, which is consistent with the changes of $\mathrm{h}$ value from $60^{\circ}$ (yellow) to $0^{\circ}$ (red). However, the statistical analysis of all sprouting treatments showed no difference.

The lowest value of hue angle (h) is $30.75^{\circ} \pm 0.93$, i.e. sprouting at week 4 , which means that the lower h value is the more dominant the red color becomes $\left(0^{\circ}-30^{\circ}=\right.$ red, $30^{\circ}-60^{\circ}=$ yellow), whereas the second-lowest is the sprouting treatment at week 3 at $34.37 \pm 0.09$. Nevertheless, this graph pattern was consistent with the results of the analysis of anthocyanin content and a* value. By its standard deviation, the treatment at week 3 may serve as an alternative option.

\subsection{Anthocyanin profile}

The results of anthocyanin characterization (sprouting at week 3) using LC-MS/MS are provided in Figure 1. Figure 1a reveals that the ion fragmentation [M $-\mathrm{X}]^{+}$is $\mathrm{m} / \mathrm{z} 286.50$ to 287.50 and that the molecular ion peaks $[\mathrm{M}]^{+}$is $\mathrm{m} / \mathrm{z} 449$, so it is confirmed that the constituent of purple sweet potato anthocyanin is Cyanidin-3-0-glucoside. While Figure $1 \mathrm{~b}$ reveals that the ion fragmentation $[\mathrm{M}-\mathrm{X}]^{+}$is $\mathrm{m} / \mathrm{z} 300.50$ to 301.50 and that the molecular ion peaks $[\mathrm{M}]^{+}$is $\mathrm{m} / \mathrm{z} 625$, but it cannot be determined whether the results are Peonidin-30-glucoside, Peonidin-3-0-(c-6"-O-coumaroyl)glucoside, Peonidin-3-0-(t-6"-O-coumaroyl)-glucoside, or Petunidin-3-0-(6"-O-coumaroyl)-glucoside. Whereas Figure $1 \mathrm{c}$ reveals that the ion fragmentation $[\mathrm{M}-\mathrm{X}]^{+}$is $\mathrm{m} /$ z 462.50 to 463.50 and that the molecular ion peaks $[\mathrm{M}]^{+}$ is $\mathrm{m} / \mathrm{z} 625$, so these results confirmed that the constituent of anthocyanin is Peonidin-3,5-0-diglucoside. Based on this anthocyanin profile of the Ayamurasaki variety of

Table 2. The average values of color intensity and color attributes $\left(a^{*}, L^{*}, b^{*}\right.$, and $\left.h\right)$ during sprouting*

\begin{tabular}{cccccc}
\hline Sprouting Week & Color Intensity & $\mathrm{a}^{*}$ value & $\mathrm{L}^{*}$ value & $\mathrm{b}^{*}$ value & $\mathrm{h}\left({ }^{\mathrm{o}}\right)$ value \\
\hline 1 & $0.60 \pm 0.6^{\mathrm{a}}$ & $7.30 \pm 0.3^{\mathrm{a}}$ & $18.5 \pm 2.45^{\mathrm{a}}$ & $6.7 \pm 0.86^{\mathrm{a}}$ & $46.24 \pm 0.4^{\mathrm{e}}$ \\
2 & $0.60 \pm 0.6^{\mathrm{a}}$ & $9.70 \pm 1.06^{\mathrm{a}}$ & $20.9 \pm 1.10^{\mathrm{a}}$ & $6.5 \pm 0.61^{\mathrm{a}}$ & $38.3 \pm 0.48^{\mathrm{d}}$ \\
3 & $0.70 \pm 0.7^{\mathrm{c}}$ & $12.8 \pm 0.49^{\mathrm{b}}$ & $21.2 \pm 2.45^{\mathrm{a}}$ & $6.5 \pm 0.61^{\mathrm{a}}$ & $34,37 \pm 0.0^{\mathrm{b}}$ \\
4 & $0.72 \pm 0.72^{\mathrm{c}}$ & $12.25 \pm 0.4^{\mathrm{b}}$ & $21.5 \pm 2.45^{\mathrm{a}}$ & $5.8 \pm 1.84^{\mathrm{a}}$ & $30.75 \pm 0.9^{\mathrm{a}}$ \\
5 & $0.67 \pm 0.67^{\mathrm{b}}$ & $9.40 \pm 1.71^{\mathrm{a}}$ & $21.4 \pm 2.45^{\mathrm{a}}$ & $6.0 \pm 1.22^{\mathrm{a}}$ & $36.56 \pm 0.6^{\mathrm{c}}$ \\
6 & $0.54 \pm 0.54^{\mathrm{a}}$ & $9.10 \pm 1.10^{\mathrm{a}}$ & $21.4 \pm 1.59^{\mathrm{a}}$ & $6.2 \pm 1.02^{\mathrm{a}}$ & $39.0 \pm 0.29^{\mathrm{d}}$ \\
\hline
\end{tabular}

* Values are means with standard deviation from three different samples. Different alphabet superscript in one column indicate significant difference $(p<0.05)$. 
purple sweet potato, it was found there are two ascertained constituents of the anthocyanin of the Ayamurasaki purple sweet potato, which are Cyanidin-30-glucoside and Peonidin-3,5-0-diglucoside. Both components of the anthocyanin are essential for the health and color size of the red. Yashimoto et al. (1999) reported that Cyanidin has the ability as an anti-cancer compound.

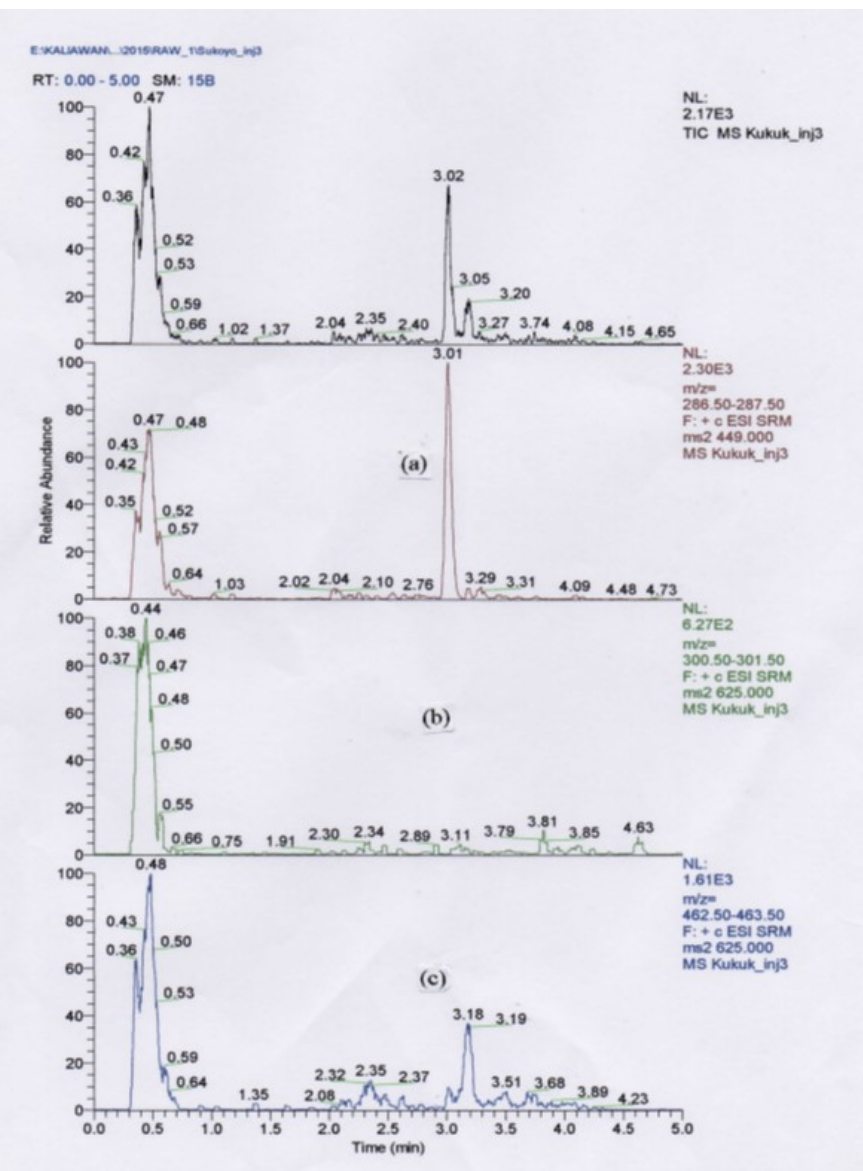

Figure 1. Chromatogram of the anthocyanin of Ayamurasaki purple sweet potato (sprouting at week 3): (a) $[\mathrm{M}-\mathrm{X}]^{+}$is $\mathrm{m} / \mathrm{z}$ 286.50 to 287.50 and molecular ion peaks $[\mathrm{M}]^{+}$is $\mathrm{m} / \mathrm{z} 449$ (Cyanidin-3-0-glucoside), (b) $[\mathrm{M}-\mathrm{X}]^{+}$is $\mathrm{m} / \mathrm{z} 300.50$ to 301.50 and molecular ion peaks $[\mathrm{M}]^{+}$is $\mathrm{m} / \mathrm{z} 625$ (the anthocyanin constituent component cannot be determined), (c) $[\mathrm{M}-\mathrm{X}]^{+}$is $\mathrm{m} / \mathrm{z} 462.50$ to 463.50 and molecular ion peaks $[\mathrm{M}]^{+}$is $\mathrm{m} / \mathrm{z} 625$ (Peonidin -3,5-0-diglucoside).

\section{Conclusion}

The conclusion of this study that sprouting treatment at week 3, yielded the highest values from total anthocyanin, antioxidant activities, color intensity, and $a^{*}$ value. The results of LC-MS/MS test confirmed that the main constituents of the anthocyanin of Ayamurasaki purple sweet potato are Cyanidin-3-0-glucoside and Peonidin-3,5-0-diglucoside. It is recommended to perform further studies on the activity of anthocyaninforming enzymes activity during sprouting, such as PAL enzyme (phenylalanine ammonia lyase).

\section{References}

Abdel-Aal, E.S.M. and Hucl, P. (1999). A Rapid method for Quantifying total anthocyanins in blue Aleurone and Purple pericarp wheats. Cereal Chemistry, 76(3), 350-354.

https://doi.org/10.1094/

CCHEM.1999.76.3.350

Andarwulan, N., Kusnandar, F. and Herawati, D. (2011). Food Analysis.Jakarta: Dian Rakyat.

Begam, M.N. and Sharanavan, P.S. (2011). Effect of sugar mill effluent on morphological and biochemical changes of groundnut Arachis hypogaea. Journal of Ecotoxicology and Environmental Monitoring, 21(3), 287-290.

Bland-Williams, W., Cuvelier, M.E. and Berset, C. (1995). Use of a free radical method to evaluate antioxidant activity. Lebersmittel-WissenschaftUndTechnologie, 29, 25-30. https://doi.org/10.1016/ S0023-6438(95)80008-5

FAO (1984). Specification for identity and purity of food colours. FAO of The United Nations. Rome. Food and Nutrition Paper, 31(1),1-145.

Jirapa, K., Jarae, Y., Phanee, R. and Jirasak, K. (2016). Changes of bioactive components in germinated paddy rice. International Food Research Journal, 23 (1), 229-236.

Kartika, U. (2013). Cancer cases in Indonesia are on the rise. Retrieved on March 23, 2013 from Kompas Webstie: http://health.kompas.com

Katsube, N., Iwashita, K.,Tsushida, T., Yamaki, K. and Kobori, M. (2003). Induction of apoptosis in cancer cells by bilberry (Vaccinium myrtillus) and the anthocyanins. Journal Agricultural Food Chemistry, 51(1), 68-75. https://doi.org/10.1021/jf025781x

Kubasek, W.L., Shirley, B.W., McKillop, A., Goodman, H.M., Briggs, W. and Ausubel, F.M. (1992). Regulation of flavonoid biosynthetic genes in germinating arabidopsis seedlings. Plant Cell, 4, 1229-1236. https://doi.org/10.1105/tpc.4.10.1229

Ling, Y., Chen, R., Susan, R.M., Carlos, M.U., Ping Pei, U.V.R. Vijaya, S., Gary, D.S., Kenneth, K.C. and Zhongfa, L. (2009). A Rapid and sensitive LC-MS/ MS method for quantification of four anthocyanins and its application in a clinical pharmacology study of a bioadhesive black raspberry gel. Journal Chromatography B Analytical Technology Biomedical Life Science, 877(31), 4027-4034. https://doi.org/10.1016/j.jchromb.2009.10.026

Parmoon, G., Ebadi, A., Jahanbakhsh, S. and Davari, M. (2013). The effect of seed priming and accelerated aging on germination and physiochemical changes in milk thistle (Silybummarianum). Notulae Scientia Biolgicae, 5(2), 204-211.

Phattayakorn, K., Pajanyor, P., Wongtecha, S., Prommakool, A. and Saveboworn, W. (2016). Effect 
of germination on total phenolic content and antioxidant properties of 'Hang' rice. International Food Research Journal, 23(1), 406-409.

Suda, I., Oki, T., Masuda, M., Kobayashi, M., Nishiba Y. and Furata, S. (2003). Physiological functionality of Purple-fleshed sweet potatoes containing anthocyanin and utilization in foods. Japan Agricultural Research Quarterly (JARQ), 37(3), 167 -173. https://doi.org/10.6090/jarq.37.167

Suryanti, V., Marliyana, S.D. and Putri, H.E. (2016). Effect of germination on antioxidant activity, total phenolics, $\beta$-carotene, ascorbic acid and $\alpha$ tocopherol contents of lead tree sprouts (Leucaenaleucocephala (lmk.) de Wit). International Food Research Journal, 23(1), 167172.

Umnajkitikorn, K., Bualang, F. Kobkiat, S. (2013). Enhancing antioxidant properties of germinate Thai rice (Oryza sativa L.) cv. Kum Doi Saket with salinity. Journal Rice Research, 1, 103. https:// doi.org/ 10.4172/jrr.100010

Vichit, W. and Saewan, N. (2016). Effect of germination on antioxidant, anti-inflammatory and keratinocyte proliferation of rice. International Food Research Journal, 23(5), 2006-2015.

World Health Organisation (WHO). (2014). Imminent global cancer 'disaster' reflects aging, lifestyle factors. The World cancer report. Retrieved on April 8, 2014 from: http://edition.cnn.com/2014/02/04/ health/who-world-cancer-report/.

Yashimoto, M., Okuna, S., Yoshinaga, M., Yamakawa, O., Yamaguchi, M. and Yamada, J. (1999). Antimutagenicity of sweet potato (Ipomoea batatas) root. Bioscience Biotechnology Biochemistry, 63, 541-543.

Yudiono, K. (2011). Extraction Anthocyanin from Purple Sweet Potato (Ipomoea batatas cv. Ayamurasaki) by Subcritical Water Technique. Jurnal Teknologi Pangan 2(1), 1-30.

Zhang, Z., Christopher, C.W. and Harold, C. (2002). Biochemical changes during storage of sweet potato roots differing in dry matter content. Postharvest Biology and Technology, 24, 317-325. https:// doi.org/10.6090/jarq.37.167 